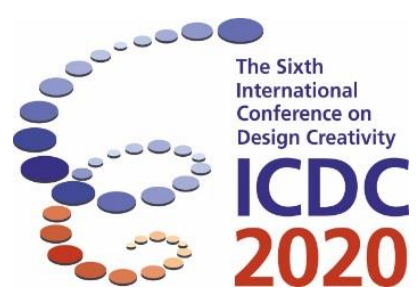

\title{
Literature review: Existing methods using VR to enhance creativity
}

\author{
Zhengya Gong and Georgi V. Georgiev \\ Center for Ubiquitous Computing, University of Oulu, Finland
}

\begin{abstract}
Virtual reality (VR) technology has introduced a range of equipment, contexts, and stimuli with possible applications in the context of design creativity. In response, recent studies have investigated VR as a tool that can be applied to enhance creativity. As a part of such research, this paper reviews existing studies and provides a state-of-the-art literature review based on the componential theory of creativity. Based on studies that investigate the use VR to enhance creativity, we found that VR can be used to improve specific factors to enhance creativity, and a natural environment can be considered a positive factor for enhancing creativity. Therefore, we propose a hypothesis that VR technology could be a useful method to simulate nature for enhancing creativity; experimentation based on the hypothesis is expected to be conducted in the future.
\end{abstract}

Keywords: virtual reality, creativity, simulated nature, immersion, context

\section{Introduction}

The present study aims to investigate the relationship between virtual reality (VR) technology in terms of context, stimuli, and design creativity. In its basic implementation, VR simulates a virtual environment with a computer to provide users a sense of immersion. Further, tremendous progress has been achieved in VR, and it has gradually emerged as a new domain in the field of science and technology, thereby leading to an increasing demand for VR in various industries (e.g., Andone et al., 2018; Georgieva \& Georgiev, 2020; Guegan et al., 2016; Pensieri \& Pennacchini, 2014). Therefore, many studies are attempting to determine methods for enhancing creativity using features of VR such as immersion, interaction, and multiple sensors, which can help improve professional knowledge and creative skills, stimulate motivation, and create a friendly social environment.

Creativity is an essential aspect of the designed world, and it is defined as "a useful novelty." The initial stages in the research in this area focused on the characteristics and cognitive ability of a person, such as their mental flexibility, in terms of the creative outcome (Wu \& Huang, 2017). Several scholars have attempted to determine factors that affect creativity during the process. For example, Amabile proposed the componential theory of creativity (Amabile, 2012) that four significant factors can affect creativity, and it has been widely adopted and applied in many research studies relevant to creativity. The physical environment has been identified as a measurable factor that influences creativity; however, few studies have focused on using VR to simulate physical environment (nature) for enhancing creativity. Therefore, this research is carried out in the following two stages:

1. Reviewing existing articles that aim to verify the effectiveness of VR in enhancing creativity;

2. Proposing a hypothesis that using VR to simulate nature is a potential method for enhancing creativity. 


\section{Factors affecting creativity}

According to the componential theory of creativity, although three individual factors (domain-relevant skills, creativity-relevant process, and task motivation), and the social environment without individuals affect creativity, some specific aspects of the physical environment are considered to have positive effects in enhancing creativity (Amabile, 2012). The creativity process also includes several subprocesses such as problems or task identification, preparation, response generation, response validation, communication, and outcome. All sub-processes are affected by the abovementioned factors, for example, the problem or task identification can be affected by task motivation; preparation can be affected by domain-relevant skills and physical environment; response generation can be affected by task motivation and creativity-relevant processes; and response validation, and communication can be affected by domain-relevant skills and social environment (Amabile, 2012). Further, the factors are also influenced by one another. Thus, the creative process is complicated and can occur in any order and can often randomly recur until the creative outcomes have been completed successfully (Figure 1). This implies that improving one of the factors can aid in enhancing creativity.

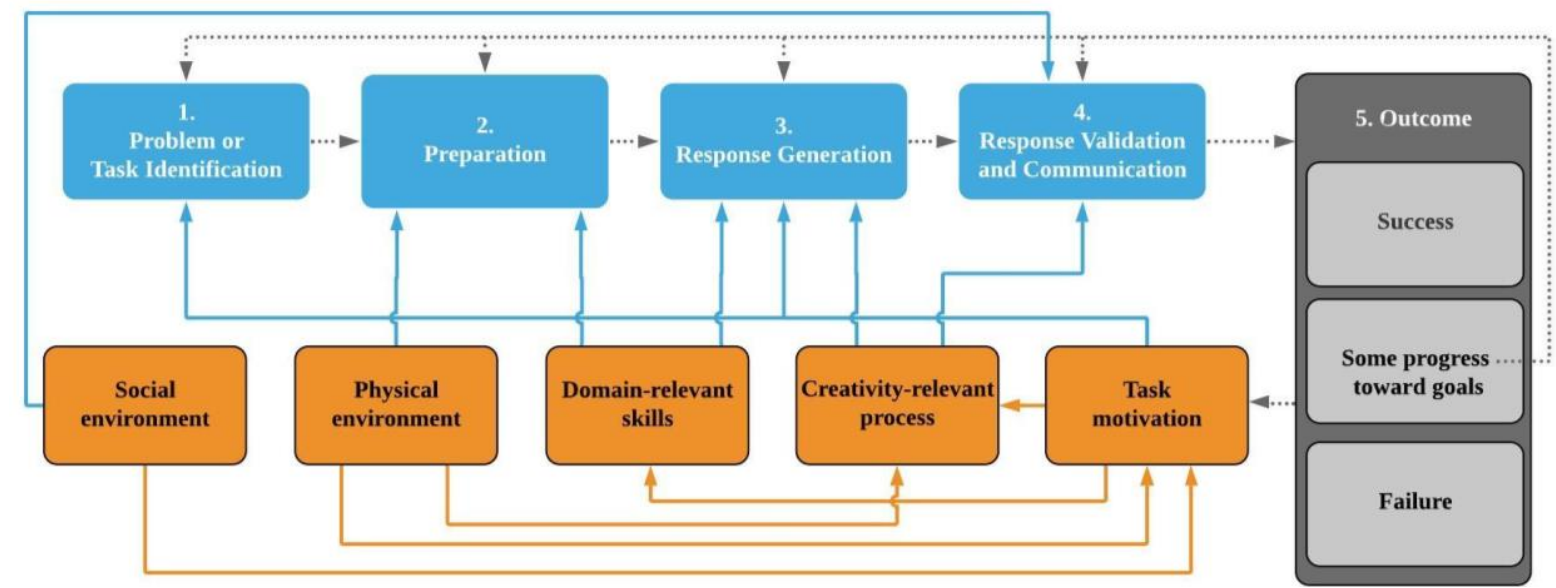

Figure 1. Interaction between steps of creativity process and the components of creativity. The dashed lines indicate the steps in the creativity process, the solid blue lines present the factors that affect the creativity process, and the solid orange lines denote the interaction between factors. Derived from

Amabile's componential theory of creativity (Amabile, 2012).

Many researchers focus on enhancing creativity based on these factors. For example, certain videogames enhance the cognitive mechanism related to the creativity-relevant processes (e.g., visual stimuli and visual processes), and subsequently, improve creativity performance (Yeh, 2015). In addition, the results of an investigation, which surveys the relationship between the supervisor and the employee, indicate that a leader-member exchange enables employees to enhance creativity. Thus, a better social environment and a high-level of task motivation can enhance the creativity of employees (Gu et al., 2015). Another test divides subjects into three groups (drama, visual arts, and drama integrated visual arts), and the results verify that learning in the arts offers multiple enhancements to creativity-relevant processes such as creative thinking and personalities (Hui et al., 2015). Furthermore, some studies focus on new technologies to inspire creativity. For example, 3D printing evokes human imagination and feelings such as enthusiasm and engagement, which can inspire creative ideas (Georgiev \& Taura, 2015). Based on the componential theory of creativity (Amabile, 2012), all these feelings are included in creativity-relevant processes. Moreover, the 3D printing course developed a range of design techniques in education to expand the expertise supporting creativity (Ford \& Minshall, 2019).

\section{Existing methods using VR to improve creativity}

Recently, there have been many concerns and a longstanding requirement to use VR for enhancing creativity (Alahuhta et al., 2014). A comprehensive literature review of how VR has been applied to 
enhancing creativity currently does not exist. This paper reviews prior research, and subsequently, divides these articles into five groups based on the componential theory of creativity (Amabile, 2012). Creativity is a comprehensive ability peculiar to human beings. Creativity refers to the ability to generate new ideas, new things, or solutions to an open-ended task (Amabile, 2012), and it is a comprehensive optimization of complex multi-factors such as knowledge, intelligence, ability, and excellent personality - a necessary ability to complete creative activities successfully.

VR is described as a computer-simulated stage wherein users can be enabled to interact with the simulated environment using special electronic equipment, such as a head-mounted display and/or gloves fitted with sensors in a virtual space. Although further studies are required, using VR to help individuals enhance real-world training, learning, and inspiring creativity is considered an easy, less expensive, and an intelligent solution (Alahuhta et al., 2014).

\subsection{Literature review process}

Literature reviews focus on a topic and provide a theoretical knowledge for relevant research, discussing the current status of knowledge in a specific topic, representing research findings, and providing directions for future work (Fink, 2019). The literature review is a process of collecting data, performing descriptive analysis, selecting categories, and evaluating materials, which aims to identify patterns, topics, and issues in the literature.

In the first stage, an initial scan of academic literature related to VR and creativity was conducted. This involved a literature search for keywords composed of "virtual reality" \& creativity"; "virtual reality" \& "innovation"; "virtual environment" \& "creativity"; "virtual environment" \& "innovation"; "virtual world" \& "creativity"; and "virtual world" \& " innovation" in journal databases such as the Google Scholar" ${ }^{\mathrm{TM}}$, British Education Index, and JSTOR for papers published in and between 2014 to 2020. During the initial scan phase, 68 research articles were identified and acquired. A preliminary analysis of these papers revealed that VR was employed to enhance creativity. Through a category selection process, the research studies were divided into five categories based on the componential theory of creativity (Amabile, 2012). They were: 1) Using VR to develop domain-relevant skills for improving creativity; 2) Using VR to increase creativity-relevant processes for improving creativity; 3) Using VR to excite task motivation for improving creativity; 4) Using VR to support the social environment for improving creativity; 5) Using VR to create the physical environment for improving creativity.

In the second stage of the literature review, a systematic process was adopted to deepen the collect detailed materials from the dispersed literature sources. The bibliography of the original articles was traced for relevant citations, and the same keyword search was performed in the journal and conference proceedings of all collected articles. This process was an iterative process of literature retrieval followed by keyword retrieval in publications and conferences until no articles could be identified. After reading the articles, we found that some articles were updated or focused only on a specific area, such as disabled individuals. Therefore, we excluded these articles and included only 20 articles (Figure 2) for the review.

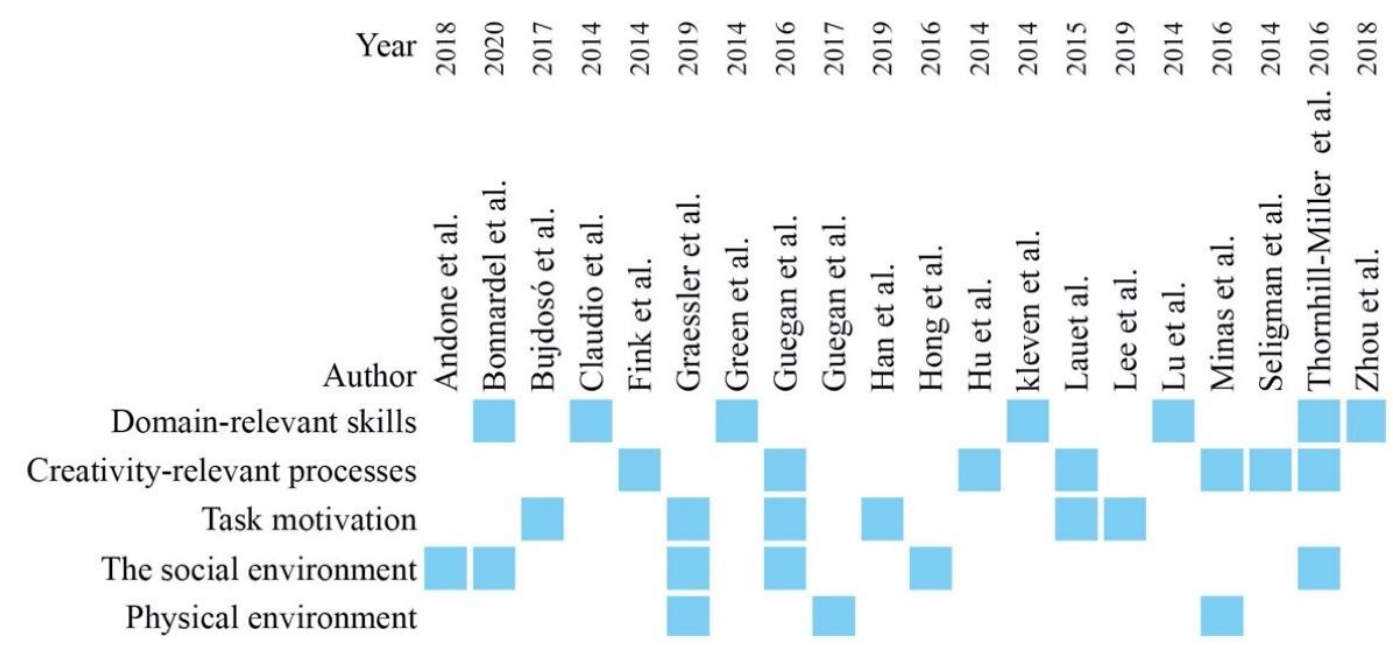

Figure 2. Groups of factors and their coverage in the background studies. 


\subsection{Using VR to develop domain-relevant skills for improving creativity}

According to the componential theory of creativity, domain-relevant skills are the professional skills of an individual, such as knowledge, expertise, intelligence, and talent in a specific area. They can be inspired by task motivation and can help individuals establish and activate stored knowledge and search for possible problem-solutions for creativity.

Considerable work has focused on approaches to integrate VR in education to develop professional skills and to enhance creativity ( $\mathrm{Lu}$ et al., 2014). As VR can simulate a real-world that is challenging to develop in the physical world, it can lead to the enhancement of typical learning and knowledge improvement (Thornhill-Miller \& Dupont, 2016). For example, designing an educational application using VR could provide interaction between educators and students, and this could help improve the accumulation of practical knowledge; the feedback from students that participated in this study indicated that they could procure knowledge easily and were willing to spend more time on practice (Zhou et al., 2018). Further, some articles focused on specific subjects such as medical (Kleven, 2014, Pensieri \& Pennacchini, 2014) and nurse training (Green et al., 2013). These articles mentioned that VR could simulate the real world without being dangerous, expensive, or resulting in social issues to gain professional knowledge. It is suggested that the improvement of professional knowledge can allow individuals to retain more domain-relevant skills to generate new ideas and methods to solve problems. Therefore, using VR can help improve the domain-relevant skills and subsequently, enhance creativity.

\subsection{Using VR to increase creativity-relevant processes for improving creativity}

Creativity-relevant processes include cognitive styles and personality characteristics such as independence, adventure, and different perspectives on problem-solving; these characteristics affect response generation in the creative process and can be influenced by task motivation (Amabile, 2012) and physical environment.

Recent studies reported that increasing creativity-relevant processes could enhance creativity. For example, Hu and others (2016) stated that sensitivity and fluency-included in creative thinking abilities - could affect creativity. By comparing two university classes (the experimental class and the control class), they found that the VR-integrated creative thinking instruction enables students to freely observe, operate, and interact with objects from the first-person perspective. This process could increase the sensitivity and fluency of students and induce imagination. This enables them to develop creative concepts and subsequently enhances creativity (Hu et al., 2016).

A study using ActiveWorld $\odot$ provided a virtual platform for students to create avatars that help individuals communicate, evaluate, seek information, and broaden their horizons. The results verified that the simulated environment, similar to a game-like environment, further promotes interests, contributing significantly to learning experiences. The students were in agreement that the VR platform encouraged them to explore and evaluate ideas during the learning process (Lau \& Lee, 2015). Another study based on setting up an avatar in virtual worlds such as Second Life indicated that the mutable sense of self could be employed to influence changes in viewpoints; further, they reported that cocorrelation increases in creativity-relevant capacities such as empathy and imagination by immersion (Thornhill-Miller \& Dupont, 2016). Similarly, another investigation examined the creativity of engineers to evaluate the effect of avatars in a virtual environment (Guegan et al., 2016). This research revealed that training in the virtual environment not only improves creativity-relevant processes, such as personality characteristics and cognitive styles, but also enhances creativity.

Meanwhile, according to previous studies, a flow state enables people to deliver a higher creative performance (Seligman \& Csikszentmihalyi, 2014); however, the attention and meditation during the creativity process can affect the creativity performance (Fink \& Benedek, 2014). An investigation examined the connection of creativity and the three factors (flow, attention, and meditation) using the VR system, and compared the paper-and-pencil control group and the VR condition group. The VR supported condition was more beneficial to lead the observation from multiple angles and obtain different perspectives on the issues. The students could integrate knowledge and generate novel ideas in the creative processes (Andone et al., 2018). Moreover, creating a virtual environment improved the student learning curve, resulting in a focused and creative-relevant process, which could enhance creativity (Yang et al., 2018). 


\subsection{Using VR to excite task motivation for improving creativity}

Task motivation is described as the internal reason for performing a task or solving a problem, such as interests and challenges, which can complete the self-challenge and make the individual feel satisfied. It is affected by three factors - social environment, physical environment, and creativity outcome - in the creative process and influences the problem or task identification and response generation.

Task motivation fosters the creativity of an individual. Some studies considered that VR created immersion could be a useful method for increasing the interests and enjoyment of an individual. In addition, the new method and an atypical environment are exciting, and they help in fostering creativity. Further, VR can be employed in creativity to generate immersion-inspired individuals, to explore the virtual world and communicate with others. Lau and colleagues mentioned that when students are in an unfamiliar environment such as a virtual world, they experience exhilaration, which indicates exploring the creative environment can be a challenging task that promotes student motivation, inspires creative potential, and enhances their creativity (Lau \& Lee, 2015). In addition, VR has become a popular tool in education as it is interactive, immersive, and supports creativity. In the context of creativity, Lee et al. mentioned that immersive systems are interesting, allowing individuals to acquire a stronger motivation and a better creativity; they proposed measuring the flow experience using two factors (the breadth and depth of ideas) in immersive systems (Lee \& Chau, 2019). Another research also emphasized that subjects strive to create solutions in the immersion environment, and they find it more interesting, exciting, and challenging than that under usual circumstances (Bujdosó et al., 2017). In addition, users were pleased to attain satisfaction with the creative processes, and they believed that the virtual environment provides an exciting challenge to inspire them to perform better during the creative processes, thereby enhancing creativity (Han, 2019).

\subsection{Using VR to support the social environment for improving creativity}

The social environment not only refers to the work or study environment (e.g., friendly work environment, strict hierarchy), but also includes all extrinsic motivations (e.g., conversations, a low-risk attitude of managers). Some of these could be a hindrance, such as excessive time pressure or demanding leaders, which contrasts with a collaborative environment, with freedom to share comments and similar motivations that could stimulate creativity (Amabile, 2012).

Although many aspects of extrinsic motivations need to be tested, some of these have been regarded as useful methods to enhance creativity in recent years. One of the most evident examples for the enhancement of creativity through VR is to support an environment wherein individuals can contribute to an idea generation activity and share ideas online with others, who belong to different regions and different cultures, to enhance creativity (Andone et al., 2018). Moreover, another researcher, focused on creating avatars in a virtual environment and indicated that designers in a simulated environment could easily interact with each other and gather information from users, which could then help them find cues and details to design products more actively (Bonnardel \& Pichot, 2020).

There are multiple extrinsic motivations for individuals to enhance creativity using VR. For example, a study explored enablers and barriers focusing on architectural design, and the authors concluded that students attempted to determine specific methods together, co-designed, and then evaluated each other. This encouraged them to collect information, evaluate data, and comment freely to design effectively (Hong et al., 2016). The VR videos of natural contexts have been used as stimuli in the early stages of design discussions (Yamada, et al., 2017). In another experiment (Andone et al., 2018), the students said: "I liked the way the project turned out and I enjoyed that I developed my creativity more," and "I learned that AR/VR is accessible to everyone. I enjoyed the fact that we could work with someone thousands of miles away." This indicates that VR simulated a virtual world that could help students communicate freely, share more information and comments, promote cooperation, and as a result, enhance creativity.

\subsection{Using VR to create the physical environment for improving creativity}

It is verified that the physical environment can be a positive factor in influencing creativity. Previously studies have proved that a suitable physical environment encourages people to enhance their creativity (Amabile, 2012). 
Although the effect of the physical environment is lower than that of the socio-organizational work environment and creative personality, some specific aspects of the physical environment are associated with creativity. For instance, certain plants, a direct view from windows, spacious interior design, and air circulation can be positive factors in enhancing the creativity of employees (Thornhill-Miller \& Dupont, 2016). There are few research studies that focus on using VR to create a suitable physical environment to improve creativity, while Minas, Dennis \& Massey (2016) proposed hypotheses. They compared the creativity of teams in two virtual environments, and the results showed that the "openness" physical environment enabled teams to generate more novel, workable, and relevant ideas than teams in a closed environment (Minas, Dennis \& Massey, 2016). Another experiment was conducted by Guegan, Nelson, \& Lubart (2017), who believe that "priming" can explain the relationship between environmental cues and creativity, which means when individuals are exposed to current environments, it can affect the following behaviour and perception. They also designed three environments (creativityconducive environment, virtual control environment and real control environment) to compare the subjective perception of their creative performance and the objective creative performance. The results revealed that subjects explored idea categories in greater depth rather than produce more ideas, and they proposed that using VR to design the specific environments that are very different from the real working environment, such as under the ocean, or in the forest, can potentially affect creative performance.

\section{Discussion}

This article summarized the existing methods of using VR in enhancing creativity, and it provides a clearer understanding of how VR is used to improve the five aspects to enhance creativity. Meanwhile, in the literature review process, although there is little direct evidence to prove that nature can enhance creativity, we found that the relationship between nature and creativity is implicitly linked. Therefore, we propose a hypothesis: using VR to simulate nature will enhance creativity.

First, in terms of the visual aspect, an experiment indicated that viewing pictures of nature could improve cognitive abilities (Berman et al., 2008). Other articles also proposed that nature has the potential to promote creativity performance (McCoy \& Evans, 2002). For example, nature can inspire visual and exploratory interests as well as challenges, stimulating intellectual and cognitive abilities and thereby promoting creative behaviour. Second, in terms of hearing, the sounds of nature are pleasant and release stress, and they also evoke positive emotions (Nilsson \& Berglund, 2006). Finally, in terms of the senses, such as the feelings of touch and smell, a survey (Plambech \& Van Den Bosch, 2015) targeting Danish creative professionals investigated the effect of nature in creative processes, such as the preparation phase. The results demonstrated that creative ability could be enhanced in nature. In the survey, the participants expressed that they were relaxed and acquired a number of new ideas, not just through the visual aspect, but also through the smell of fresh air, the feel of the wind, and the smells of the trees and flowers, and that all these factors enabled them to involve in the creative process peacefully and calmly. Based on the componential theory of creativity (Amabile, 2012), improved cognitive abilities included in the creativity-relevant processes, and positive emotions related to task motivation, could be an important driving force for enhanced creativity.

As discussed above, nature could enhance creativity in individuals, and hence, using VR to simulate nature will also forest creativity, because VR can simulate nature and allow individuals to immerse themselves in a virtual environment that can inspire visual interests, feeling of excitement and sense of freshness as well as entertaining, stimulating intellectual and cognitive abilities, and thereby promoting creative behaviour that helps improve professional knowledge and creative skills, stimulate motivation, and enhance creativity. Moreover, according to "priming," if the individual is involved in a suitable environment, such as the simulated nature, it could influence their behaviours and perceptions and encourage them to be creative.

\section{Conclusions and further work}

This article summarized the existing research conducted on the application of VR in enhancing creativity based on the componential theory of creativity. Through synthesizing diverse and fragmented literature related to the topic from 2014 to 2020, this literature review explains how VR has been employed in enhancing creativity. As described in Section 2, there is evidence that five factors can affect the 
creativity process, thereby influencing the creativity. Meanwhile, based on these five aspects, we collected 20 articles to explain how VR can be used to enhance creativity in Section 3, and we hypothesized that using VR to simulate nature will enhance creativity, in Section 4.

We plan to conduct a comparative experiment (brainstorming in a simulated natural environment and brainstorming in another VR environment) that allows the subjects to generate ideas and compares the results of two groups: the simulated nature group and the control group. Further, we believe that the following results would be obtained: 1) the simulated nature group has a higher level in the state of flow; 2) the simulated nature group is more easily focused on the task and involved with greater attention than the control group; 3) participants in the simulated nature group feel relaxed, which can enable them to create; and 4) participants in the simulated nature group can produce high-quality creative works. We believe that these obtained results would suggest the use of VR to simulate nature for enhancing creativity.

\section{Acknowledgements}

This study has been financially supported by Academy of Finland 6Genesis Flagship (grant 318927). We would like to thank Dr. Vijayakumar Nanjappan for the discussions on the revised version of the manuscript.

\section{References}

Amabile, T. M. (2012). Componential theory of creativity. Harvard Business School, 12(96), 1-10.

Andone, D., Vert, S., Frydenberg, M., \& Vasiu, R. (2018, July). Open Virtual Reality Project to Improve Students' Skills. In 2018 IEEE 18th International Conference on Advanced Learning Technologies (ICALT) (pp. 6-10). IEEE. http://dx.doi.org/10.1109/ICALT.2018.00008

Alahuhta, P., Nordbäck, E., Sivunen, A., \& Surakka, T. (2014). Fostering team creativity in virtual worlds. Journal For Virtual Worlds Research, 7(3). https://doi.org/10.4101/jvwr.v7i3.7062

Berman, M. G., Jonides, J., \& Kaplan, S. (2008). The cognitive benefits of interacting with nature. Psychological science, 19(12), 1207-1212. https://doi.org/10.1111/j.1467-9280.2008.02225.x

Bonnardel, N., \& Pichot, N. (2020). Enhancing collaborative creativity with virtual dynamic personas. Applied Ergonomics, 82, 102949. https://doi.org/10.1016/j.apergo.2019.102949

Bujdosó, G., Novac, O. C., \& Szimkovics, T. (2017). Developing cognitive processes for improving inventive thinking in system development using a collaborative virtual reality system. In 2017 8th IEEE International Conference on Cognitive Infocommunications (CogInfoCom), Debrecen, Hungary, (pp. 000079-000084). IEEE. https://doi.org/10.1109/CogInfoCom.2017.8268220

Pensieri, C., \& Pennacchini, M. (2014). Overview: Virtual reality in medicine. Journal of Virtual Worlds Research, 7(1). https://doi.org/10.4101/jvwr.v7i1.6364

Fink, A. (2019). Conducting research literature reviews: From the internet to paper. Sage publications.

Fink, A., \& Benedek, M. (2014). EEG alpha power and creative ideation. Neuroscience \& Biobehavioral Reviews, 44, 111-123. https://doi.org/10.1016/j.neubiorev.2012.12.002

Ford, S., \& Minshall, T. (2019). Invited review article: Where and how 3D printing is used in teaching and education. Additive Manufacturing, 25, 131-150. https://doi.org/10.1016/j.addma.2018.10.028

Georgiev, G. V., \& Taura, T. (2015). Using idea materialization to enhance design creativity. In Proceedings of the 20th International Conference on Engineering Design (ICED 15), Milan, Italy, 27-30.07.15 (pp. 349-358).

Graessler, I., \& Taplick, P. (2019). Supporting Creativity with Virtual Reality Technology. In Proceedings of the Design Society: International Conference on Engineering Design (Vol. 1, No. 1, pp. 2011-2020). Cambridge University Press. https://doi.org/10.1017/dsi.2019.207

Georgieva, I., \& Georgiev, G. V. (2020). Reconstructing Personal Stories in Virtual Reality as a Mechanism to Recover the Self. International Journal of Environmental Research and Public Health, 17(1), 26. https://doi.org/10.3390/ijerph17010026

Green, J., Wyllie, A., \& Jackson, D. (2014). Virtual worlds: A new frontier for nurse education? Collegian, 21(2), 135-141. https://doi.org/10.1016/j.colegn.2013.11.004

Gu, Q., Tang, T. L. P., \& Jiang, W. (2015). Does moral leadership enhance employee creativity? Employee identification with leader and leader-member exchange (LMX) in the Chinese context. Journal of Business Ethics, 126(3), 513-529. https://doi.org/10.1007/s10551-013-1967-9

Guegan, J., Buisine, S., Mantelet, F., Maranzana, N., \& Segonds, F. (2016). Avatar-mediated creativity: When embodying inventors makes engineers more creative. Computers in Human Behavior, 61, 165-175. https://doi.org/10.1016/j.chb.2016.03.024 
Guegan, J., Nelson, J., \& Lubart, T. (2017). The relationship between contextual cues in virtual environments and creative processes. Cyberpsychology, Behavior, and Social Networking, 20(3), 202-206. https://doi.org/10.1089/cyber.2016.0503

Han, H. C. S. (2019). Virtual World Construction and the Relationship to Creativity in Art Education. Canadian Review of Art Education: Research \& Issues, 46(1). http://dx.dop.org/10.26443/crae.v46i1.44

Hong, S. W., Jeong, Y., Kalay, Y. E., Jung, S., \& Lee, J. (2016). Enablers and barriers of the multi-user virtual environment for exploratory creativity in architectural design collaboration. CoDesign, 12(3), 151-170. https://doi.org/10.1080/15710882.2015.1081239

Hu, R., Wu, Y. Y., \& Shieh, C. J. (2016). Effects of Virtual Reality Integrated Creative Thinking Instruction on Students' Creative Thinking Abilities. Eurasia Journal of Mathematics, Science \& Technology Education, 12(3), 447-486. https://doi.org/10.12973/eurasia.2016.1226a

Hui, A. N., He, M. W., \& Ye, S. S. (2015). Arts education and creativity enhancement in young children in Hong Kong. Educational Psychology, 35(3), 315-327. https://doi.org/10.1080/01443410.2013.875518

Kleven, N. F. (2014). Virtual University hospital as an arena for medical training and health education (Master's thesis, Norwegian University of Science and Technolo). http://hdl.handle.net/11250/253752

Lau, K. W., \& Lee, P. Y. (2015). The use of virtual reality for creating unusual environmental stimulation to motivate students to explore creative ideas. Interactive Learning Environments, 23(1), 3-18. https://doi.org/10.1080/10494820.2012.745426

Lee, P. T. Y., \& Chau, M. (2019). Can Immersive Systems Improve Creativity Performance? An Exploratory Study. In Americas Conference on Information Systems (Vol. 2019).

Lu, S., Harter, D., Kosito, P., \& Kotturu, P. (2014). Developing low-cost training environments: How do effector and visual realism influence the perceptual grounding of actions? Journal of Cognitive Education and Psychology, 13(1), 3-18. http://dx.doi.org/10.1891/1945-8959.13.1.3

McCoy, J. M., \& Evans, G. W. (2002). The potential role of the physical environment in fostering creativity. Creativity Research Journal, 14(3-4), 409-426. https://doi.org/10.1207/S15326934CRJ1434 11

Minas, R. K., Dennis, A. R., \& Massey, A. P. (2016). Opening the mind: designing 3D virtual environments to enhance team creativity. In 2016 49th Hawaii International Conference on System Sciences (HICSS), Koloa, HI, USA (pp. 247-256). IEEE. http://dx.doi.org10.1109/HICSS.2016.38

Nilsson, M. E., \& Berglund, B. (2006). Soundscape quality in suburban green areas and city parks. Acta Acustica united with Acustica, 92(6), 903-911.

Plambech, T., \& Van Den Bosch, C. C. K. (2015). The impact of nature on creativity-A study among Danish creative professionals. Urban Forestry \& Urban Greening, 255-263. https://doi.org/10.1016/j.ufug.2015.02.006

Seligman, M. E., \& Csikszentmihalyi, M. (2014). Positive psychology: An introduction. In Flow and The Foundations of Positive Psychology (pp. 279-298). Springer, Dordrecht. https://doi.org/10.1007/978-94-0179088-8 18

Thornhill-Miller, B., \& Dupont, J. M. (2016). Virtual reality and the enhancement of creativity and innovation: Under recognized potential among converging technologies? Journal of Cognitive Education and Psychology, 15(1), 102-121. https://doi.org/10.1891/1945-8959.15.1.102

Wu, T. T., \& Huang, Y. M. R. (2017, June). Work in progress: Influence of cognitive concept connection, personal motivations, and personal characteristics when assessing creativity. In ASEE Annual Conference and Exposition, Conference Proceedings (Vol. 2017).

Yamada, K., Tsumaya, A., Taura, T., Shimada, K., Kaihara, T., Yokokohji, Y., \& Sato, R. (2017). An educational method for enhancing the ability to design innovative products. In Proceedings of the 21st International Conference on Engineering Design (ICED 17), Vancouver, Canada, 21-25.08.2017 (pp. 049-058).

Yang, X., Lin, L., Cheng, P. Y., Yang, X., Ren, Y., \& Huang, Y. M. (2018). Examining creativity through a virtual reality support system. Educational Technology Research and Development, 66(5), 1231-1254. https://doi.org/10.1007/s11423-018-9604-z

Yeh, C. S. H. (2015). Exploring the effects of videogame play on creativity performance and emotional responses. Computers in Human Behavior, 53, 396-407. https://doi.org/10.1016/j.chb.2015.07.024

Zhou, Y., Ji, S., Xu, T., \& Wang, Z. (2018). Promoting knowledge construction: A model for using virtual reality interaction to enhance learning. Procedia computer science, 239-246. https://doi.org/10.1016/j.procs.2018.04.035 